\title{
ÍNDICE ANUAL 2013 \\ Problemas del desarrollo \\ REVISTA LATINOAMERICANA DE ECONOMÍA \\ VOLUMEN 44
}

\section{I. ÍNDICE POR AUTORES}

\section{Artículos}

Astroulakis, Nikos (2013), Desafiando a la economía convencional. Un paradigma ético del desarrollo, núm. 175, México, IIEc-UNAM, octubre-diciembre, pp. 33-53.

Barrón, Antonieta (2013), Desempleo entre los jornaleros agrícolas, un fenómeno emergente, núm. 175, México, IIEc-UnAM, octubre-diciembre, pp. 55-79.

Cacciamali, Maria Cristina, y Fábio Tatei (2013), Género y salarios de la fuerza de trabajo calificada en Brasil y México, núm. 172, México, IIEc-Unam, eneromarzo, pp. 53-79.

Castillo, Juan Sebastián; Esther Aguilera, y Carmen García Cortijo (2013), Centroamérica: lo impostergable de una diversificación comercial coherente, núm. 174, México, IIEc-unam, julio-septiembre, pp. 119-138.

Correa, Gabriela, y René Núñez (2013), Migración y exclusión en China: sistema HUKOU, núm. 172, México, IIEc-unam, enero-marzo, pp. 105-123.

Dabat, Alejandro, y Paulo Leal (2013), Declinación de Estados Unidos: contexto histórico mundial, núm. 174, México, IIEc-UNAM, julio-septiembre, pp. 61-88.

De Angelis, Ignacio; Mariana Calvento, y Mariano Roark (2013), ¿Hacia un nuevo modelo de desarrollo? Desde la teoría de la regulación. Argentina 20032010, núm. 173, México, IIEc-unam, abril-junio, pp. 31-56.

Espino, Alma (2013), Brechas salariales en Uruguay: género, segregación y desajustes por calificación, núm. 174, México, IIEC-UnAM, julio-septiembre, pp. 89-117. 
Fisher, Eloy (2013), Estabilización automática y seguridad social: Brasil, México, Costa Rica y Chile, núm. 173, México, IIEc-unam, abril-junio, pp. 9-29.

Fuente, Mario Enrique, y David Barkin (2013), La minería como factor de desarrollo en la Sierra Juárez de Oaxaca. Una valoración ética, núm. 172, México, IIEC-UNAM, enero-marzo, pp. 123-144.

García, Ariel, y Alejandro Rofman (2013), Poder y espacio. Hacia una revisión teórica de la cuestión regional en Argentina, núm. 175, México, IIEc-unam, octubre-diciembre, pp. 101-124.

González Temprano, Antonio (2013), Política Agraria Común y la de cohesión frente a la Estrategia Europa 2020, núm. 173, México, IIEc-UnAM, abril-junio, pp. 105-132.

Hernández, José Luis (2013), La migración de trabajadores calificados como un problema del desarrollo, núm. 172, México, IIEc-UnAM, enero-marzo, pp. 81-103.

Mántey, Guadalupe (2013), ¿Conviene Flexibilizar el tipo de cambio para mejorar la competitividad?, núm. 175, México, IIEc-UnAM, octubre-diciembre, pp. 9-32.

Marshall, Wesley (2013), El papel de la banca pública en las crisis financieras de Argentina y Uruguay, núm. 172, México, IIEc-UnAM, enero-marzo, pp. 29-51.

Mejía, Pablo; Sandra Ochoa, y Miguel Ángel Díaz (2013), De la recesión a la recuperación: Producción y empleo en México y el Estado de México, núm. 173, México, IIEc-unam, abril-junio, pp. 133-162.

Musacchio, Andrés (2013), El ajuste: origen de la crisis europea, núm. 173, México, IIEc-UnAm, abril-junio, pp. 79-104.

Narro Robles, José; David Moctezuma Navarro, y Diego de la Fuente Stevens (2013), Descalabros y desafíos de la política social en México, núm. 174, México, IIEC-UNAM, julio-septiembre, pp. 9-34.

Nudelsman, Susana (2013), Implicaciones de la Crisis Financiera y económica global en América Latina, núm. 175, México, IIEc-UnAM, octubre-diciembre, pp. 125-146. 
Puyana, Alicia, y Agostina Constantino (2013), Sojización y enfermedad holandesa en Argentina: ¿la maldición verde?, núm. 175, México, IIEc-unam, octubre-diciembre, pp. 81-100.

Ramírez Urquidy, Martín; Manuel Bernal, y Roberto Fuentes (2013), Emprendimiento y desarrollo manufactureros en las entidades federativas de México, núm. 174, México, IIEc-Unam, julio-septiembre, pp. 167-195.

Soto, Roberto (2013), América Latina. Entre la financiarización y el financiamiento productivo, núm. 173, México, IIEc-UnAM, abril-junio, pp. 57-60.

Torres, Jaime (2013), Colombia: inserción y desequilibrios comerciales en la Cuenca del Pacífico, núm. 174, México, IIEc-unam, julio-septiembre, pp. 139-165.

Yasuhara, Tsuyoshi (2013), Inestabilidad financiera en América Latina desde una perspectiva Kaleckiana y Minskyana, núm. 172, México, IIEc-UnAm, enero-marzo, pp. 9-27.

Yoguel, Gabriel; Florencia Barletta, y Mariano Pereira (2013), De Schumpeter a los postschumpeterianos: viejas y nuevas dimensiones analíticas, núm. 174, México, IIEc-UnAM, julio-septiembre, pp. 35-59.

\section{Comentarios y debates}

Andrade, Pablo (2013), ¿Por qué es importante la historia? La economía política del desarrollo en debate, núm. 174, México, IIEC-UNAM, julio-septiembre, pp. 197-210.

Ferrer, Aldo (2013), La importancia de las ideas propias sobre el desarrollo y la globalización, núm. 173, México, IIEc-UnAM, abril-junio, pp. 163-174.

Guevara, Iris (2013), Educación superior e investigación para la competitividad productiva internacional, núm. 172, México, IIEc-UnAM, enero-marzo, pp. 145-156.

Rozo, Carlos, y Aleida Azamar (2013), El G20 en Los Cabos. Oportunidad perdida para el cambio necesario, núm. 175, México, IIEc-UnAM, octubre-diciembre, pp. 147-162. 


\section{Reseńas}

Arellano, Wilma (2013), Capitalismo del conocimiento e industria de servicios de telecomunicaciones en México, Sergio Ordóñez y Rafael Bouchain, núm. 173, México, IIEc-UnAM, abril-junio, pp. 177-179.

Aroskind, Ricardo (2013), Por qué crecieron los paises que crecieron, Julio Sevares, núm. 172, México, IIEc-UnAM, enero-marzo, pp. 166-167.

Bernal, Irma (2013), Potencialidades de desarrollo, politicas públicas y desarrollo territorial sustentable, Carlos Bustamante, Baldemar Hernández y Adolfo Sánchez (coords.), núm. 175, México, IIEc-unAm, octubre-diciembre, pp. 165-166.

Blanco, Aldo (2013), El crecimiento económico en Cuba: un análisis desde la productividad total de los factores, Yaima Doimeadiós, núm. 173, México, IIEcUNAM, abril-junio, pp. 182-185.

Chapoy, Alma (2013), Europa, deudas soberanas y financiarización, Alicia Girón y Marcia Solorza, núm. 175, México, IIEc-UnAM, octubre-diciembre, pp. 173-175.

Dávalos, Juan José (2013), Crisis, rentismo e intervencionismo neoliberal en la banca: México (1982-1999), Irma Sandoval, núm. 172, México, IIEc-unam, enero-marzo, pp. 157-159.

Delgado, Irma (2013), Retos en la exploración y producción de petróleo crudo en el sexenio 2012-2018, Fabio Barbosa Cano, núm. 174, México, IIEc-unam, julio-septiembre, pp. 224-226.

González Lima, Héctor (2013), Avances revolucionarios en América Latina, Rémy Herrera, núm. 175, México, IIEc-UnAM, octubre-diciembre, pp. 163-164.

Hernández, Santiago (2013), Arquitectura de la crisis financiera, Irma Manrique (coord.), núm. 172, México, IIEc-unAM, enero-marzo, pp. 168-170.

Hernández, Santiago (2013), Fundamentos de economía, Marcela Astudillo, Jorge Paniagua (colaborador), núm. 173, México, IIEc-UnAM, abril-junio, pp. 175-176. 
López, Alejandro (2013), Volver a Keynes. Fundamentos de la teoría general de la ocupación, el interés y el dinero, Axel Kicillof, núm. 174, México, IIEc-Unam, julio-septiembre, pp. 217-219.

Maya, José Luis (2013), Modo de desarrollo, organización territorial y cambio constituyente en el Ecuador, Ana María Larrea Maldonado, núm. 174, México, IIEC-UNAM, julio-septiembre, pp. 214-216.

Morales, Josefina (2013), La inversión extranjera directa en México 1980-2011, Samuel Lichtensztejn, núm. 174, México, IIEc-unam, julio-septiembre, pp. 220-223.

Olmos, Rafael (2013), Estudios regionales en México. Aproximaciones a las obras y sus autores, Javier Delgadillo y Felipe Torres, núm. 172, México, IIEc-Unam, enero-marzo, pp. 163-165.

Olmos, Rafael (2013), Abasto de alimentos en economía abierta. Situación en México, Felipe Torres, Yolanda Trápaga, José Gasca y Sergio Martínez, núm. 173, México, IIEc-Unam, abril-junio, pp. 186-188.

Quintana, Aderak (2013), Sistema financiero, desequilibrios globales y regulación, Alma Chapoy y Alicia Girón, núm. 173, México, IIEc-UnAM, abril-junio, pp. $180-181$.

Rodríguez, Patricia (2013), La nueva macroeconomía global. Distribución del ingreso, empleo y crecimiento, Guadalupe Mántey y Teresa López (coords.), núm. 175, México, IIEc-UnAM, octubre-diciembre, pp. 167-169.

Solís, Karol (2013), Financiamiento de la banca comercial a micro, pequeñas y medianas empresas en México, Rodrigo Fenton y Ramón Padilla, núm. 172, México, IIEc-unAm, enero-marzo, pp. 160-162.

Vázquez, Patricia (2013), Panorama actual de la integración latinoamericana y caribeña, Alfredo Guerra Borges (coordinador), núm. 174, México, IIEcUNAM, julio-septiembre, pp. 211-213.

Vázquez, Raúl (2013), Integración Latinoamericana y Caribeña. Política y Economía, José Briceño et al., núm. 175, México, IIEc-UnAM, octubre-diciembre, pp. 170-172. 


\section{II. ÍNDICE ALFABÉTICO POR TEMAS}

\section{América Latina}

Aroskind, Ricardo (2013), Por qué crecieron los paises que crecieron, Julio Sevares, núm. 172, México, IIEc-UnAM, enero-marzo, pp. 166-167.

Blanco, Aldo (2013), El crecimiento económico en Cuba: un análisis desde la productividad total de los factores, Yaima Doimeadiós, núm. 173, México, IIEcUNAM, abril-junio, pp. 182-185.

Castillo, Juan Sebastián; Esther Aguilera, y Carmen García Cortijo (2013), Centroamérica: lo impostergable de una diversificación comercial coherente, núm. 174, México, IIEc-UnAM, julio-septiembre, pp. 119-138.

García, Ariel, y Alejandro Rofman (2013), Poder y espacio. Hacia una revisión teórica de la cuestión regional en Argentina, núm. 175, México, IIEc-unam, octubre-diciembre, pp. 101-124.

González Lima, Héctor (2013), Avances revolucionarios en América Latina, Rémy Herrera, núm. 175, México, IIEc-UNAM, octubre-diciembre, pp. 163-164.

Nudelsman, Susana (2013), Implicaciones de la Crisis Financiera y económica global en América Latina, núm. 175, México, IIEc-UnAM, octubre-diciembre, pp. $125-146$.

Torres, Jaime (2013), Colombia: inserción y desequilibrios comerciales en la Cuenca del Pacifico, núm. 174, México, IIEc-Unam, julio-septiembre, pp. 139-165.

\section{Asia}

Correa, Gabriela, y René Núnez (2013), Migración y exclusión en China: sistema HUKOU, núm. 172, México, IIEc-UnAM, enero-marzo, pp. 105-123.

\section{Desarrollo y crecimiento económico}

Astroulakis, Nikos (2013), Desafiando a la economía convencional. Un paradigma ético del desarrollo, núm. 175, México, IIEc-UnAM, octubre-diciembre, pp. 33-54. 
De Angelis, Ignacio; Mariana Calvento, y Mariano Roark (2013), ¿Hacia un nuevo modelo de desarrollo? Desde la teoría de la regulación. Argentina 20032010, núm. 173, México, IIEc-Unam, abril-junio, pp. 31-53.

Hernández, José Luis (2013), La migración de trabajadores calificados como un problema del desarrollo, núm. 172, México, IIEC-UnAM, enero-marzo, pp. 81-103.

Rozo, Carlos, y Aleida Azamar (2013), El G20 en Los Cabos. Oportunidad perdida para el cambio necesario, núm. 175, México, IIEc-UnAm, octubre-diciembre, pp. 147-162.

Vázquez, Patricia (2013), Panorama actual de la integración latinoamericana y caribeña, Alfredo Guerra Borges (coordinador), núm. 174, México, IIEcUNAM, julio-septiembre, pp. 211-213.

Vázquez, Raúl (2013), Integración Latinoamericana y Caribeña. Política y Economía, José Briceño et al., núm. 175, México, IIEc-UnAM, octubre-diciembre, pp. $170-172$.

\section{Desarrollo regional}

Barrón, Antonieta (2013), Desempleo entre los jornaleros agrícolas, un fenómeno emergente, núm. 175, México, IIEc-unaM, octubre-diciembre, pp. 55-79.

Bernal, Irma (2013), Potencialidades de desarrollo, politicas públicas y desarrollo territorial sustentable, Carlos Bustamante, Baldemar Hernández y Adolfo Sánchez (coords.), núm. 175, México, IIEc-unAM, octubre-diciembre, pp. 165-166.

Fuente, Mario Enrique, y David Barkin (2013), La minería como factor de desarrollo en la Sierra Juárez de Oaxaca. Una valoración ética, núm. 172, México, IIEC-UNAM, enero-marzo, pp. 123-144.

Maya, José Luis (2013), Modo de desarrollo, organización territorial y cambio constituyente en el Ecuador, Ana María Larrea Maldonado, núm. 174, México, IIEC-UNAM, julio-septiembre, pp. 214-216.

Mejía, Pablo; Sandra Ochoa, y Miguel Ángel Díaz (2013), De la recesión a la recuperación: Producción y empleo en México y el Estado de México, núm. 173, México, IIEC-UnAM, abril-junio, pp. 133-162. 
Olmos, Rafael (2013), Estudios regionales en México. Aproximaciones a las obras y sus autores, Javier Delgadillo y Felipe Torres, núm. 172, México, IIEc-Unam, enero-marzo, pp. 163-165.

Olmos, Rafael (2013), Abasto de alimentos en economía abierta. Situación en México, Felipe Torres, Yolanda Trápaga, José Gasca y Sergio Martínez, núm. 173, México, IIEc-unam, abril-junio, pp. 186-188.

Puyana, Alicia, y Agostina Constantino (2013), Sojización y enfermedad holandesa en Argentina: ¿la maldición verde?, núm. 175, México, IIEc-unam, octubre-diciembre, pp. 81-100.

Ramírez Urquidy, Martín; Manuel Bernal, y Roberto Fuentes (2013), Emprendimiento y desarrollo manufactureros en las entidades federativas de México, núm. 174, México, IIEc-UNAM, julio-septiembre, pp. 167-195.

\section{Economía de la energía}

Delgado, Irma (2013), Retos en la exploración y producción de petróleo crudo en el sexenio 2012-2018, Fabio Barbosa Cano, núm. 174, México, ilec-unam, julio-septiembre, pp. 224-226.

\section{Economía financiera}

Chapoy, Alma (2013), Europa, deudas soberanas y financiarización, Alicia Girón y Marcia Solorza, núm. 175, México, IIEc-unAm, octubre-diciembre, pp. 173-175.

Dávalos, Juan José (2013), Crisis, rentismo e intervencionismo neoliberal en la banca: México (1982-1999), Irma Sandoval, núm. 172, México, IIEc-unam, enero-marzo, pp. 157-159.

Hernández, Santiago (2013), Fundamentos de economía, Marcela Astudillo, Jorge Paniagua (colaborador), núm. 173, México, IIEc-unAm, abril-junio, pp. 175-176.

Hernández, Santiago (2013), Arquitectura de la crisis financiera, Irma Manrique (coord.), núm. 172, México, IIEc-unAM, enero-marzo, pp. 168-170. 
López, Alejandro (2013), Volver a Keynes. Fundamentos de la teoría general de la ocupación, el interés y el dinero, Axel Kicillof, núm. 174, México, IIEc-Unam, julio-septiembre, pp. 217-219.

Mántey, Guadalupe (2013), ¿Conviene Flexibilizar el tipo de cambio para mejorar la competitividad?, núm. 175, México, IIEc-UNAM, octubre-diciembre, pp. 9-32.

Marshall, Wesley (2013), El papel de la banca pública en las crisis financieras de Argentina y Uruguay, núm. 172, México, IIEc-UnAM, enero-marzo, pp. 29-51.

Quintana, Aderak (2013), Sistema financiero, desequilibrios globales y regulación, Alma Chapoy y Alicia Girón, núm. 173, México, IIEc-UnAM, abril-junio, pp. 180-181.

Solís, Karol (2013), Financiamiento de la banca comercial a micro, pequeñas y medianas empresas en México, Rodrigo Fenton y Ramón Padilla, núm. 172, México, IIEC-UnAM, enero-marzo, pp. 160-162.

Soto, Roberto (2013), América Latina. Entre la financiarización y el financiamiento productivo, núm. 173, México, IIEc-UnAM, abril-junio, pp. 57-60.

Yasuhara, Tsuyoshi (2013), Inestabilidad financiera en América Latina desde una perspectiva Kaleckiana y Minskyana, núm. 172, México, IIEc-UnAm, enero-marzo, pp. 9-27.

\section{Economía internacional}

Dabat, Alejandro, y Paulo Leal (2013), Declinación de Estados Unidos: contexto histórico mundial, núm. 174, México, IIEc-UnAM, julio-septiembre, pp. 61-88.

Musacchio, Andrés (2013), El ajuste: origen de la crisis europea, núm. 173, México, IIEc-UnAM, abril-junio, pp. 79-104.

\section{Estado y políticas de desarrollo}

Guevara, Iris (2013), Educación superior e investigación para la competitividad productiva internacional, núm. 172, México, IIEc-UNAM, enero-marzo, pp. 145-156. 
González Temprano, Antonio (2013), Política Agraria Común y la de cohesión frente a la Estrategia Europa 2020, núm. 173, México, IIEc-UnAM, abril-junio, pp. 105-132.

Narro Robles, José; David Moctezuma Navarro, y Diego de la Fuente Stevens (2013), Descalabros y desafíos de la politica social en México, núm. 174, México, IIEC-UNAM, julio-septiembre, pp. 9-34.

\section{Estudios de género y discriminación}

Cacciamali, Maria Cristina, y Fábio Tatei (2013), Género y salarios de la fuerza de trabajo calificada en Brasil y México, núm. 172, México, IIEc-Unam, eneromarzo, pp. 53-79.

Espino, Alma (2013), Brechas salariales en Uruguay: género, segregación y desajustes por calificación, núm. 174, México, IIEC-UNAM, julio-septiembre, pp. 89-117.

\section{Historia económica}

Andrade, Pablo (2013), ¿Por qué es importante la historia? La economía politica del desarrollo en debate, núm. 174, México, IIEc-unam, julio-septiembre, pp. 197-210.

Ferrer, Aldo (2013), La importancia de las ideas propias sobre el desarrollo y la globalización, núm. 173, México, IIEc-UnAM, abril-junio, pp. 163-174.

Yoguel, Gabriel; Florencia Barletta, y Mariano Pereira (2013), De Schumpeter a los postschumpeterianos: viejas y nuevas dimensiones analiticas, núm. 174, México, IIEc-UnAM, julio-septiembre, pp. 35-59.

\section{Innovación y tecnología}

Arellano, Wilma (2013), Capitalismo del conocimiento e industria de servicios de telecomunicaciones en México, Sergio Ordóñez y Rafael Bouchain, núm. 173, México, IIEc-unam, abril-junio, pp. 177-179. 


\section{Macroeconomía}

Fisher, Eloy (2013), Estabilización automática y seguridad social: Brasil, México, Costa Rica y Chile, núm. 173, México, IIEc-unam, abril-junio, pp. 9-29.

Morales, Josefina (2013), La inversión extranjera directa en México 1980-2011, Samuel Lichtensztejn, núm. 174, México, IIEc-unam, julio-septiembre, pp. 220-223.

Rodríguez, Patricia (2013), La nueva macroeconomía global. Distribución del ingreso, empleo y crecimiento, Guadalupe Mántey y Teresa López (coords.), núm. 175, México, IIEC-UnAM, octubre-diciembre, pp. 167-169. 
